\title{
Juger les crimes contre les Juifs : des Allemands devant les tribunaux belges, 1941-1951
}

\section{Marie-Anne Weisers}

\section{(2) OpenEdition}

\section{Journals}

Édition électronique

URL : http://journals.openedition.org/cmc/379

DOI : $10.4000 / \mathrm{cmc} .379$

ISSN : 2684-3080

\section{Éditeur}

Fondation de la Mémoire Contemporaine

\section{Édition imprimée}

Date de publication : 1 décembre 2014

Pagination : 245-247

ISSN : 1377-1256

\section{Référence électronique}

Marie-Anne Weisers, « Juger les crimes contre les Juifs : des Allemands devant les tribunaux belges, 1941-1951 », Les Cahiers de la Mémoire Contemporaine [En ligne], 11 | 2014, mis en ligne le 05 novembre 2019, consulté le 14 septembre 2020. URL : http://journals.openedition.org/cmc/379 


\section{Présentations de thèses doctorales}

Marie-Anne Weisers, Juger les crimes contre les Juifs : des Allemandsdevant les tribunaux belges, 1941-1951.

Université libre de Bruxelles, 2014 (directeur : prof. Pieter Lagrou).

L'étude porte sur le jugement après la Seconde Guerre mondiale des crimes commis contre les Juifs par l'occupant allemand. L'objectif de la recherche est de proposer une hypothèse, un regard et un éclairage à la fois nouveau et différent sur le travail effectué par les juridictions militaires belges, en le replaçant dans un contexte et un processus historique qui remonte à la Première Guerre mondiale. Elle constitue aussi une contribution à la connaissance de ce que furent les persécutions antijuives en Belgique, en particulier sur le mode opératoire des arrestations individuelles. Cette étude est donc consacrée avant tout au jugement du crime, mais également au crime lui-même.

Les procès qui ont eu lieu après la guerre ont généralement été qualifiés d'échecs au point de vue de la sanction et de la reconnaissance juridique de la responsabilité des autorités allemandes dans le processus d'extermination des Juifs de Belgique. L'idée véhiculée jusqu'à présent consiste à considérer ce bilan comme globalement négatif soit parce que les priorités auraient été placées ailleurs, soit parce que les magistrats auraient été indifférents à la question juive, ou n'auraient en tout cas rien fait pour reconnaître juridiquement les persécutions raciales en Belgique. Or, certains éléments importants figurant dans les archives infirment cette conclusion. La question centrale qui traverse toute la thèse est de savoir si la justice belge a eu la volonté, l'ambition et le projet de juger les crimes commis contre les Juifs et, si oui, pourquoi cette ambition a eu des résultats décevants ou en tout cas a donné l'impression à la postérité que la tentative n'avait jamais été entreprise.

Il est possible d'évaluer le bilan des procès menés contre les criminels de guerre allemands uniquement en termes de peines. Pris sous cet angle, il est effectivement permis d'aboutir à un constat d'échec. Il peut aussi être procédé à une évaluation du travail de la justice uni- 
quement en fonction des qualifications juridiques appliquées stricto sensu aux faits commis. Dans ce cas, le bilan est mitigé. Une troisième option, celle qui a été prise dans cette recherche, est de tenter dans un premier temps de comprendre quelles sont les raisons de ce bilan mitigé pour ensuite se plonger au cœur d'un procès et analyser concrètement, pas à pas, la manière dont les magistrats du parquet et du siège ont accompli leur travail. Dans cette optique, s'ajoute aux sanctions prononcées et aux qualifications juridiques, le facteur des démarches et des efforts entrepris pour parvenir à une sanction qui puisse satisfaire aux exigences d'une société éprise de justice.

La thèse est divisée en deux parties. La première partie porte sur la préparation du jugement des criminels de guerre, avant, pendant et dans les deux années qui suivent la Seconde Guerre mondiale, ceci jusqu'au vote de la loi belge du 20 juin 1947 sur les crimes de guerre. Les différents chapitres sont centrés sur l'étude du cadre juridique international puis national qui précède les procès belges, lesquels se dérouleront entre 1948 et 1951.

La seconde partie de la thèse est consacrée à l'étude de deux procès. Le premier est celui d'Otto Siegburg, un policier allemand, chasseur de Juifs, chef d'une équipe d'arrestation de la section juive de la Sipo (Sicherheitspolizei : Police de sécurité) de Bruxelles. Le choix de ce procès s'explique par son caractère exceptionnel. Ce policier nazi a en effet été condamné par le Conseil de guerre de Bruxelles, non pour crime de guerre, mais pour crime contre l'humanité, ce qui constitue une exception non seulement au niveau belge, mais aussi au niveau des procès qui eurent lieu durant cette période dans les autres pays d'Europe. Ce fait juridique était jusqu'à présent ignoré de tous, révélant une vraie volonté de la part de certains magistrats belges de sanctionner les auteurs de crimes raciaux, contredisant du même coup l'idée selon laquelle il n'y aurait pas eu en Belgique de reconnaissance judiciaire des persécutions contre les Juifs.

Le second procès est celui d'un de ses collègues, le ressortissant luxembourgeois Lambert Namur. Arrivé en Belgique en 1934, il intègre la Judenabteilung en 1942 et obtient les mêmes compétences que celles attribuées aux autres policiers allemands de la Sipo. Siegburg et Lambert ont la même activité qui consiste à arrêter, de jour comme de 
nuit, des Juifs qu'ils emmènent ensuite dans les caves de la Gestapo situées avenue Louise, lesquels sont ensuite transférés à la caserne Dossin à Malines pour y être déportés vers les camps de la mort. Il a dès lors paru pertinent de comparer le sort judiciaire de ces deux hommes et d'examiner la manière dont furent menés leurs procès par la justice belge et luxembourgeoise.

Pénétrer à l'intérieur des procès, les analyser minutieusement du premier jour de l'instruction jusqu'au dernier jour du procès, faire du point de vue méthodologique de la micro-histoire, a permis non seulement de comparer les choix judiciaires et législatifs de deux pays limitrophes, mais aussi d'obtenir quantité d'informations liées au mode opératoire des arrestations raciales. La retranscription des témoignages laisse en effet entrevoir l'ampleur et la dimension propre à l'activité quotidienne, routinière, des deux accusés; celle des exécutants. Du récit des témoins ressort une brutalité, une violence inouïe que l'on peut suivre presque pas à pas. Les sources judiciaires, d'une richesse exceptionnelle, permettent à l'historien d'identifier une à une les victimes et de connaître leur histoire individuelle. Elles aident incontestablement à reconstruire et à éclairer l'événement, celui du déroulement en Belgique du processus de destruction des Juifs d'Europe. 